\title{
Predicting excitatory phase resetting curves in bursting neurons
} Selva K Maran*1, Fred H Sieling², Astrid A Prinz ${ }^{2,3}$ and Carmen C Canavier ${ }^{1}$

\author{
Address: ${ }^{1}$ Neuroscience Center for Excellence, LSU Health Sciences Center, New Orleans, LA, 70112, USA, ${ }^{2}$ Wallace H. Coulter Department of \\ Biomedical Engineering, Georgia Tech and Emory University, Atlanta, GA 30332, USA and ${ }^{3}$ Department of Biology, Emory University, Atlanta, \\ GA, 30322, USA \\ Email: Selva K Maran* - sselan@lsuhsc.edu \\ * Corresponding author
}

from Seventeenth Annual Computational Neuroscience Meeting: CNS*2008

Portland, OR, USA. 19-24 July 2008

Published: II July 2008

BMC Neuroscience 2008, 9(SuppI I):PI34 doi:I0.I 186/I47I-2202-9-SI-PI34

This abstract is available from: http://www.biomedcentral.com/I47I-2202/9/SI/PI34

(C) 2008 Maran et al; licensee BioMed Central Ltd.

\section{Background}

The phase resetting curves (PRCs) of neural oscillators can predict the phase locking within a network [1], but for bursting neurons the duration and shape of the burst may change as a result of the feedback within a network, thus it would be useful to understand how these changes impact the resetting. A previous study [2] characterized the responses of bursting neurons to inhibitory pulses as that of a relaxation oscillator whose limit cycle had a depolarized (bursting) and hyperpolarized (silent) branch. Inhibitions applied during the burst produced a switch to the hyperpolarized branch and prevented a
A

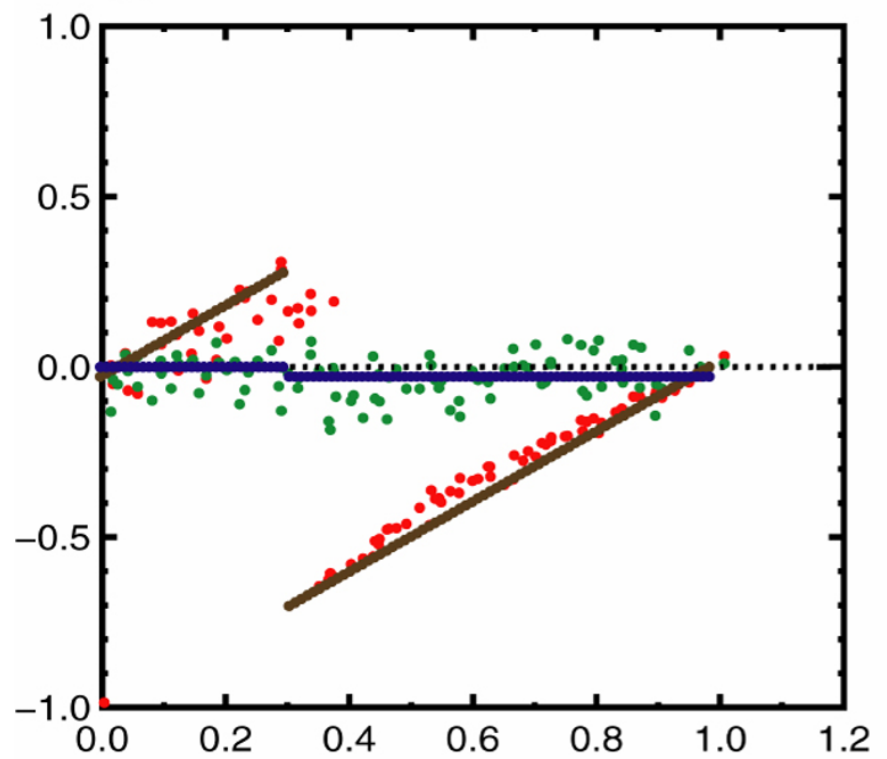

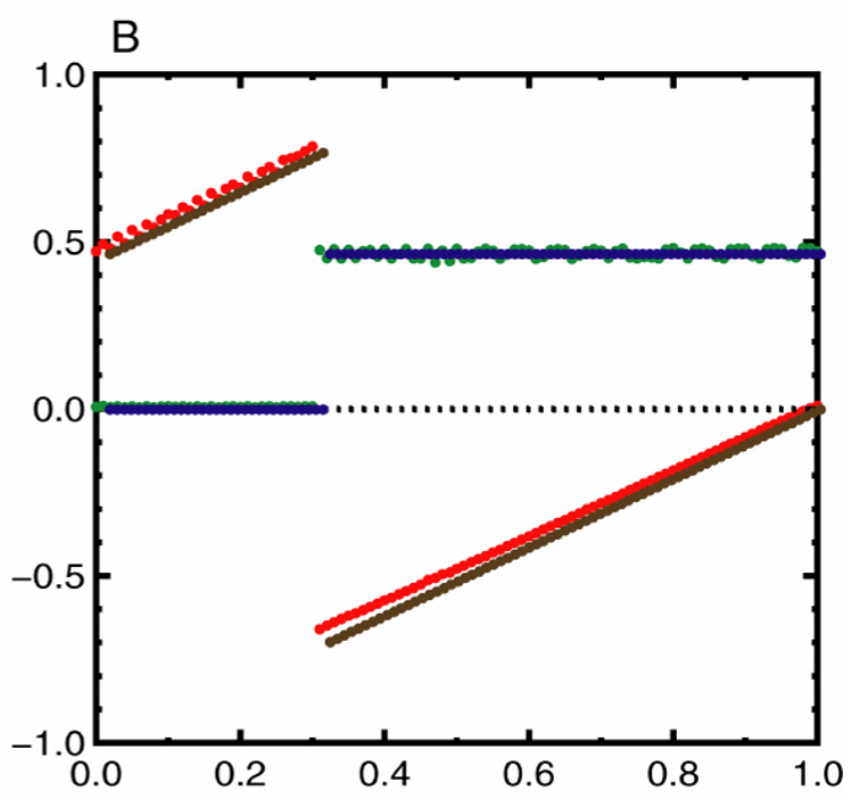

Figure I

Phase Resetting Curves for strong and long case. Predicted (fl, f2) and Observed (fl, f2) first (fl) and Second (f2) order Resetting. A) Biological Neuron B) Model Neuron. 
switch back to the depolarized branch until the inhibition was turned off, whereas inhibitions during the silent phase had little effect. Here the response of bursting neurons to excitation is characterized.

\section{Methods}

First and second order PRCs for excitatory inputs of different strength and duration were constructed by using the dynamic clamp to inject an artificial synaptic conductance pulse into bursting pyloric pacemaker neurons in the stomatogastric ganglion of the crab and lobster. A model neuron [3] was used to gain insight into the phenomenology of phase resetting.

\section{Results}

The observed PRCs were explained by assuming different trajectories in the phase space. Inputs that were relatively strong and long appeared to drive the neuron to a tonically spiking limit cycle. When the input was turned off, an essentially fixed period of time elapsed before the next burst, suggesting that a constant trajectory led from the tonic attractor to the original limit cycle. This produced bilinear PRCs that were successfully predicted using these assumptions (Fig 1). A weaker long pulse drove the trajectory to a faster, smaller amplitude bursting limit cycle. For a weaker and shorter pulse, early inputs produced a delay by prolonging the burst whereas later inputs produced an advance by shortening the interburst interval, resulting in a cubic PRC. Finally, strong, brief inputs during the interburst produced a transient shallow burst cycle rather than the instantaneous reset to the depolarized branch that was exhibited by the model. In summary, phase resetting of bursting neurons in response to excitation is more complex and less predictable than in response to inhibition.

\section{References}

I. Oprisan SA, Prinz AA, Canavier CC: Phase resetting and phase locking in hybrid circuits of one model and one biological neuron. Biophys J 2004, 87(4):2283-98.

2. Oprisan SA, Thirumalai V, Canavier CC: Dynamics from a time series: can we extract the phase resetting curve from a time series? Biophys J 2003, 84(5):2919-28.

3. Prinz AA, Billimoria CP, Marder E: Alternative to hand-tuning conductance-based models: construction and analysis of databases of model neurons. I Neurophysiol 2003, 90(6):3998-40I5.
Publish with BioMed Central and every scientist can read your work free of charge

"BioMed Central will be the most significant development for disseminating the results of biomedical research in our lifetime. " Sir Paul Nurse, Cancer Research UK

Your research papers will be:

- available free of charge to the entire biomedical community

- peer reviewed and published immediately upon acceptance

- cited in PubMed and archived on PubMed Central

- yours - you keep the copyright

Submit your manuscript here:

http://www.biomedcentral.com/info/publishing_adv.asp 